\title{
An Educational Proposal on Active Citizenship for Unaccompanied Minors
}

\author{
Lucia De Marchi \\ Venice University, Ph.D School in Educational Sciences
}

\begin{abstract}
The reality of unaccompanied minors is clearly present throughout the Italian territory. This research based on the mixed method has highlighted the difficulties in training these minors in active citizenship, both because of the scarcity of resources, both for hostile national and local legislation to their social integration. The transition to the age of majority is always critical, and many minors are at risk of social exclusion. It is necessary that the various stakeholders define all together an interdisciplinary training that allow unaccompanied minors to improve their skills on active citizenship, not only for social inclusion, but also active engagement as citizens in the future
\end{abstract}

\section{Introduction}

The reality of unaccompanied minors is clearly present throughout the territory of Italy. The ANCI Report 2011 shows that $80 \%$ of the provincial capitals have welcomed unaccompanied minors in the last two years. The regions interested by the phenomenon are Lazio (19.4\%), Emilia Romagna $(17,00 \%)$, Lombardia (9.8\%) and Puglia $(9.0 \%)$. The situation of Sicily is very particular, which is the goal of most of the landings. Foreign minors are likely to be male, just below the threshold of most ages. The countries of origin are: Afghanistan, Bangladesh, Albania, Egypt, Morocco and Kosovo.

In the various Italian realities that I analyzed with my research, only in one case there are some "apartments of transition" in which the boys do experience of living alone, after the period in the reception facilities. In all other cases, the transition to the age of majority is seen as an effective accompanying the new age boy to the door of the centre. The actions that operators can implement as soon as they accept a minor, are to build a minimum of social network. Become important personal contacts that the operators in the reception facilities have with organizations, institutions and volunteers. Otherwise a new age should live in the street or underground, above all where there are some problems with the legal permit for age.

\section{Migration trends}

In the Report of the United Nations 2011[1], it was recorded that during the decade from 2000 to
2010 were 3.4 million migrants who have reached every year more developed regions of the globe, especially directed towards North America. During the same period, 32 of the 45 most developed countries have accepted international migration. Besides the United States, other target areas were Australia, Canada, New Zealand, the European Union, Russia and Japan. In the complex of international migration, it should be noted also the complex shifts to countries in the developing world.

Bangladesh, China, India, Mexico and the Philippines are the origin countries of a great number of migrants. Asia during the decade 20002010, was the continent with the most immigrants (1.6 million per year), followed by Latin America (1.1 million a year) and Africa (0.6 million per year). In addition to international migration, a considerable number of refugees flees their country of origin for massing along the borders of neighboring countries.

The introduction to the IOM Report 2010 [2] highlights the fact that international migration have become a complex phenomenon, and growing on a large scale. Whose causes are to be found in the socio-economic dynamics taking place on a global level, as well as climate change, the growing demographic disparities, as well as the technological revolution.

As pointed out in the last Human Development Report 2013 [3], the South of the world is experiencing an economic development, making protagonists not only the BRICS, but also other countries such as Bangladesh, Chile, Ghana, Turkey. A network of commercial traffic was created between South and South, and this means that there will be new destinations for international migration.

According to the UN, the young people who enter in the labor market in emerging countries by 2025 , will be more than the current workforce in industrialized countries. If the workforce in the most advanced and industrialized, will be approximately 600 million people in less industrialized countries will grow from 2.4 billion in 2005 to 3.6 billion in 2040. It will be especially a young workforce that will seek employment not only in the North of the World, but also in the South that is experiencing a new phase of economic growth and development.

\subsection{Migrant minors}

The decision to migrate to the major cities of the country or to undertake voyages of up to several months to other countries by children, especially 
teenagers, is determined by various factors that may be of a social nature, individual or even due to environment where these kids end up living. From UNICEF Report 2011 [4], entitled Adolescence. The time of opportunity, emphasizes that in the world there are about 33 million children and teenagers who migrate with their families and alone.

The group of under 20 years old is the most representative band of migration from Africa (28\%), Asia and Oceania (20\%). In the UNICEF Report cited above, the age group between 10 to 19 years, accounted for $18 \%$ of the world population in 2009 and a teenager in six lives in less developed countries, especially in Africa and Asia. It is also estimated that by 2050 , approximately $70 \%$ of these children will live in urban areas, especially in developing countries.

But what are the risks to the survival of these minors? First, the conditions of life and health that are often precarious and although progress has been made at the level of vaccination of children, yet there are many risks to which they may be subject adolescents. Due to poor nutrition and healthy, especially for girls than boys, which makes them even weaker whereas in certain cultures is consented to the marriage of girls. This means addressing both sex that exposes them to virulent diseases and even death, both early pregnancies that put at risk the lives of both the newborn, both the mother - child.

In addition, socio-economic conditions of poverty, especially for teenagers and for their families, becomes a luxury being able to allow their children to continue their studies at secondary school. In fact, even the guys that I met in the various contexts of fieldwork, had an underlying condition of poor schooling. Most of the time they had dropped out of school to go to work and help their families, or because they had ended up on the street.

In UNICEF report 2009 states that although there has been a massive campaign to promote the attendance of primary school worldwide, many millions of teenagers have not completed and this is not allowed then to be able to go to secondary school and have a better education with which to compare then with the society in which they live. This finding is especially heavy in Africa, where more than 70 million teenagers are out of school and this figure affects the countries of the zone of sub-Saharan Africa.

In analyzing the conditions of children worldwide, UNICEF Report 2012 [5], describes what are the hardships that migrant children face when they arrive in urban areas. We read in the third chapter: " According to a recent analysis of census data and family members from 12 countries, one child every five migrants between 12 and 14 years old, and half of those aged 15 to 17 , they moved without parents.
Often children and young people follow established patterns of migration. In West Africa and South Asia, where the number of independent child migration are particularly high , the majority of migrant children leave home between 13 and 17 years. Many of them grow up in deprived rural areas where it is common to travel in search of work to supplement the family income for part of the year , especially during times of crisis, or for longer. It is estimated that in India alone, at least four million children migrate seasonally, either alone or with their families".

The case studies collected in this survey confirm what this report reiterates about the causes that lead these children to migrate: "Migration is an attempt to secure a better life, in terms of educational or economic opportunities, or simply to escape from the poverty. Others move because of family circumstances $[\ldots]$, or as a result of conflicts or natural disasters and food shortages".

\subsection{Unaccompanied Minors in Italy}

The statistical data of unaccompanied minors in Italy did not reflect reality in its entirety and complexity. At the European level under the name unaccompanied minors or separated children are referred to "third country nationals or stateless persons below the age of eighteen, who arrive on the territory of the Member States unaccompanied by an adult responsible for them whether by law or uses, so do not effectively taken into the care of such a person shall be liable for, or minors who are left unaccompanied after they have entered the territory of the Member States ". In the pages of the website of the Ministry of Labour and Welfare is specified for unaccompanied minors "means a minor who is not a citizen of Italian or other European Union member states that, by failing to submit the application for political asylum, is for any reason in State's territory without assistance and representation on the part of parents or other adults legally responsible for him under the laws in force in the Italian".

This definition of unaccompanied foreign minors in fact excludes unaccompanied asylum seekers, those who are victims of trafficking, European unaccompanied minors and the estimates compared to children living in hiding as erratic and then. In the Second EMN Italy Report 2010 [6], compared to data collected in the database of the dynamic exComitato Minori Stranieri (CMS), it is reported that "this figure should not be considered exhaustive and therefore undervalued compared to the actual extent of the phenomenon, as on one side are not included MSNA asylum seekers, victims of trafficking and EU citizens, on the other hand does not take into account all those unaccompanied minors who have 
never been in contact with the national reception system”.

\subsection{Arabic Spring}

In recent years, the Mediterranean region has been affected by the upheavals of the Arab Spring that led to decree a state of emergency for our country with the emergency response plan in North Africa, to deal with the numerous landings on the Italian coast and in particular on Lampedusa. According to the XVII ISMU Report on Migration 2011[7]: "The Arab Spring has disrupted the early months of 2011 by radically changing relatively stable state systems such as Tunisia, Libya and Egypt. This has led to an intensification of the smuggling of migrants towards Italy and Europe , coming mostly from Tunisia and Libya. As landing place chosen by the " ships of shame " predominates Lampedusa, with 370 out of 507 total landings (73\%), followed by the Sicilian coast with 84 landings and Calabrian coast with 25 landings. The male component of 2011 is higher ( $90 \%$ ) compared to the previous year (about $72 \%$ ).

In March of 2008 was established by the Ministry of Labour and Welfare in consultation with ANCI (National Association of Italian Municipalities), the National Program for the protection of unaccompanied minors. The program involves a large part of the reality of Italian municipalities. In recent years, detailed reports are disseminated by ANCI about the Italian situation of unaccompanied minors .

In the last report of 2011 , on a survey conducted on approximately $73.5 \%$ of Italian municipalities, shows that $14.2 \%$ of these municipalities has taken charge of unaccompanied minors by activating pathways of action and / or reception . In 2009, 5879 children were contacted, while in 2010 there were 4588. $91.4 \%$ of these children were male, highlighting once again and so more and more pronounced than the phenomenon of unaccompanied minors is a male phenomenon. The countries of origin most were Afghanistan, Bangladesh, Albania and then Morocco, Egypt and Kosovo. These data are also confirmed for the next two years by the National Reports of CMS. If 2011 was the year of the Arab Spring with a high prevalence of children from Africa, 2012 is characterized by the considerable increase in the percentage of children Bengalis. In fact, in 2011 there were $6.6 \%$ in 2012 and rose to $18.6 \%$.

The CMS data at 31 December 2012 indicate that the total MSNA in 7575 of which were present in 5821 and 1754 structures untraceable. $18.6 \%$ of these guys came from Bangladesh, followed by Egypt (16.2\%), Afghanistan (15.7\%) followed by Albania , Somalia, Morocco and Tunisia. The figure that seems to remain constant from 2000 to the present is age-related .

\section{Research Focus. Minors in the Limbo}

In 2010, I proposed a research problem which aimed to study in depth the educational policies of the school, thinking that they would not promote the social integration of the child because of the structure of the curriculum and organization of the school system. Both the definition of the problem, both research hypothesis were formulated based on the initial experience I had gained from collaboration with a community of Venice.

As I proceeded with my fieldwork, it became increasingly obvious that my point of view was shortsighted and that I would have been liable to make the foolish decision to study the reality of MSNA with a triangulation, which included the study of the communities and of the labor market, beyond school system. Why study of the complex relationships between these three social actors, then if I wanted to focus my attention only on the school curriculum? And at the same time I was wondering if the school alone was the only source of all evil, and especially the no-social integration of MSNA. These questions became increasingly pressing .

Suddenly the problem was not so much the Italian school curriculum, but more generally as young people are trained, not only to enter on the labour market, but first and foremost as citizens of a multicultural society. The key question became how to live this multiculturalism.

Between August and September 2011, taking advantage of the summer break, I got to read several books on qualitative research has allowed me to understand that if instruments linked to this methodology would allow me to be able to understand and analyze a reality that had become very more complex than I had thought during the first year of research. At the same time I started to do some research on the internet on the basis of key words such as " global citizenship ", " citizenship ", "citizenship education ", " education for citizenship". In addition to the documents of the European Union on key competences for citizenship, I found the proceedings of a conference sponsored by Save the Children titled "Education for global citizenship and curriculum : best practices in comparison. Milan, 13 to 14 September 2010" [8].

We read in the Introduction of the same document: "Education today, more than ever, requires openness to a global dimension, supported by an ethos that makes children and young people are able to understand the phenomena of everyday life, which represent meeting between the local and global dimensions [...] Educating for citizenship means sustain learning paths to promote knowledge, skills and languages that make children and 
adolescents to exercise their rights and assume their responsibilities to ' internal reality in which they live and of which include critically the rules and values . means, not least, to promote a school that is itself laboratory and place of democracy".

Then I asked myself these two new issues: in the case of unaccompanied minors who were learning pathways that enable them to exercise their rights tomorrow and take responsibility? And the authors of these paths were the only schools with their curriculum? This was the turning point of my research because I have shifted the focus of my research from the school curriculum, the educational project that overall the various social actors along with the boy should choose as the most suitable location for the its realization not only professional, but personal. The basic question was then figure out when and if the various training programs of unaccompanied minors allowed them to become active citizens in contemporary society.

Between September and October 2011 there were two other moments of field research that confirmed what I had gained in the months before. In fact, in Florence, visiting a community, the referent of educators towards the end of his interview, she said: "They are our future society that we are forming citizenship . Citizenship is passing not only, but also through this line".

Among the various educators, unaccompanied minors are defined minors in the Limbo. Always waiting for documents that do not arrive at the mercy of regulations that change their legal status, but especially with a sword of Damocles hanging over their heads and that is called age of majority. At the age of eighteen, these minors have to go away from the community and also social services terminate the mandate with them. These neo-age the first thing they do is to abandon their studies, even if they have good results, because they must be able to work and prove that they have a residence in order to obtain a regular permit.

\section{Research Methodology}

Considering the reality and especially to investigate the subject of the research, it was necessary to integrate the qualitative to the quantitative approach to obtain comprehensive data. Cohen, Manion, Morrison's [9] claim that the search based on the mixed method recognizes and confronts the fact that reality is not only qualitative or quantitative, but it looks like a "mixed world" to investigate and then taking into account the two approaches. Although, as the authors point out, a researcher can determine that the research has a greater susceptibility to the statistics or qualitative.

In the scope of this research, the mixed approach has been interpreted as a methodological opportunity study of multiple contexts, both in terms of quality, both in the quantity to be able to collect and analyze data and then be able to describe in the comprehensive as possible, the various contexts investigated and compared between them. In the mixed method paradigm, ontology recognizes that the phenomenon studied is complex for which a single approach may be part of the same study.

With regard to epistemology - how we investigate the knowledge and phenomena - requires a combination of pragmatic methods to understand the phenomenon under study and its many facets. In order to define the framework of research, Maxwell suggests to develop an interactive model of the structure of the research, in which there are some key areas that will exchange information and then interact with each other. These five areas for the author would be: the objectives, the conceptual model, the research questions, the method and the validity.

At the end of a reflective phase of the method to be adopted, the choice was to use ethnographic research and its toolbox. The characteristic of this type of research is the ability to be modulated according to the contexts in which research is carried out in the field, providing a set of tools that can be adopted in order to enhance their effectiveness in collecting the points of view other. "Doing ethnography means describing a particular way based on a social perspective is not obvious, namely, to observe and describe social reality, on the basis of assumptions which illustrate aspects little obvious or not obvious.

The researcher has the opportunity during fieldwork to collect a "rich descriptive material " that allows him to be able to post-process theory, based on interpretations of how various cultural aspects are linked to other elements of the environment. The ethnographer, in addition to the possibility to directly investigate a particular aspect of asking people who live in a particular context, may submit, in addition, an explanation and may experience collecting other types of information about that particular aspect .

In the Seventies, anthropology has experienced a new era marked by the interpretive turn that seen in the figure of Clifford Geertz its promoter . "Observe and describe preliminary operations and are no longer marginal social research, but the heart of a problematic relationship, with open and critical objects: a report that incorporates an ongoing discussion of the position of the observer, and the random nature of its partial observations and especially the crucial nature of the practices of description, that is writing ( Dal Lago and De Biasi , 2002, p. IX)" [10]. The task of a researcher ethnographer is to unravel the tangle of significant symbols with which the cultural discourse is woven and translate it in such a way as to make it understandable to other cultural worlds. "In the 
cultural analysis, symptoms or significant signs are not aggregates of symptoms, but symbolic acts or clusters of symbolic acts, and the aim is not therapy, but the analysis of social discourse" [11]. This analysis allows us to understand "the diversity of ways in which human beings construct their lives in the act of experiencing them". Therefore, the researcher proceeds inductively from field research to the formulation of hypotheses and then to a theory that explains the complexity of social discourse. Polyphonic discourse, in which more items are compared on particular themes, such as the definition of citizenship and to be citizens.

The interpretive anthropology allows us to capture the complexity of social thought in its various shades "getting over reductionism, universalism empty or worrying naturalization" and then be able to study and analyze how global phenomena will decline to the local level". It stimulates the analysis of modernity with which the ideas and practices of modernity are appropriate and re-inserted into the local practices" in a constant proliferation. And in this process of analysis " the marginal and peripheral subjectivity, marked by numerous traditions, can be understood in their potential to build alternative economies, to deal with the basic needs, to form social groups ".

The choice, therefore, to adopt Geertz's perspective in the study of the formation of active citizenship, this was dictated by its inherent potential to seize as pressures from below - the host communities, the minors, the network operators acting in re-formulate the concept of the formation of the new being citizens of a country that belongs to the global ecumene, as defined by Ulf Hannerz. "Today", writes the Norwegian anthropologist [12] , "there is a world culture, but we need to clarify what this means : it does not mean an uniform replica of unique models, but rather an organization of diversity, increasing interconnection of different local cultures, as well as the development of cultures without a net anchoring in a particular territory. And people relate in different ways related to this variety".

The study of the reality of MSNA brings to light the fact that these guys from other worlds and cultures, are local worlds in our culture. But what is the connection between anthropology and education in the context of this research? According to Chiara Bove [13], are basically three reasons why an educator to approach and integrate its approach with the ethnographic method: 1) it offers a flexible methodological paradigm that allows to study the processes and educational interactions respecting their cultural connotation; 2) The articulation methodology and the choice of instruments are defined, along with the research question, in the course of the research in a nonlinear and flexible manner;
3) it proposes a rigorous causality that calls the exit from the ethnocentric dimension of knowledge.

With iterative cycle of theory - practice - theory, we review the whole of the methodology used, but at the same time defining the research tools. After an initial period of trial and testing, fieldwork has begun to take shape and to be structured both from the point of view of contexts to be studied, both social actors to be involved and thus the tools used to collect and to understand the research problem which was focused in a more timely manner.

In fact, the focus of the research was the study of the past school curriculum, the study of the educational project tout court that the complex of social actors defined together with the individual child. In order to investigate the various contexts of research that made up the total fieldwork, I used the various tools of mixed method. For the quantitative research: international statistical data; EU, national, reports of local authorities and data structures or different contexts. For the qualitative research: observation, interviews, case studies, field journal, laboratory on citizenship.

Triangulation multi-stakeholders for each context: shelters, schools and the world of work. Sampling: simple random, both for the operators of both boys. The age group most represented is that of unaccompanied minors aged between 15 - 17 years, as national statistics. Almost all of minors are male. The presence and prevalence of geographical areas of origin of unaccompanied minors varies according to the context of reception.

The educational and training events are complex phenomena to be studied and require flexible tools for analysis. The ethnographic method with its toolbox to realize this flexibility allows tools to be taken. Tools and techniques that can be changed during the course of work in the field of research. As already described, in the case of this research on MSNA, if the ethnographic method was judged as the most suitable with respect to the problem to be investigated, both the tools, both the research hypothesis have been revised several times and developed by progress of the study of different contexts.

\section{Data analisys}

During the fieldwork, data were collected with various techniques of qualitative research and specifically the toolbox of ethnographic research . From the observation situations, the interviews with various actors, the notes of diary and the LabCity. In addition were also collected materials of nature as statistical data concerning the reception of unaccompanied minors at both local, and national level. After the fieldwork, on the stage of data analysis it was important to decide how to proceed and especially how to set up the process of analysis of various collected data. Reading the pages written by Geertz in The Interpretation of Cultures, I started to investigate and in some way to answer the 
questions that are posed at the time of the elaboration of the overall research. "In the findings of the anthropologist the important thing is their complex specificity, the fact that they are rich in detail" writes the American anthropologist. In fact, the five contexts studied, many details were obtained at times with strong similarities, sometimes with marked differences . Surely complex because multiple entries in the field have described a wider social problem , namely, that of citizenship .

The evidence collected through interviews, discussions with the boys during the LabCity, field notes written hurriedly among the various movements, have the value of "small events" that occurred in a specific context. These little facts manage to talk about the issue of training for active citizenship, that is, the big issue. This social discourse to be interpreted by the researcher.

Cohen, Manion and Morrison argue that the data of a qualitative nature pose certain challenges. First, the data are very rich, indeed complexes for which their analysis requires a long time to select them and sort them. Secondly, the researcher in an attempt to interpret these data plays a double hermeneutic process, with which it tries to interpret in the first instance what has been said, explained, accomplished by those who are observed, which in turn has already tried to give an interpretation of his behavior or the meaning of a precise terms used. In the second instance, the researcher makes a work of translation of meaning to make it understandable to his audience. Therefore, this work of interpretation is the emic and ethic union carried out together.

\subsection{Qualitative Research}

The work of qualitative analysis of the collected material was carried out in several stages. First collected materials were distinguished by type. This is because an interview cannot be analyzed with the same procedure by which we observe, study and bring out significant elements of a program of brainstorming, a drawing or a diary note.

Secondly, there was a reflection if to perform the analysis manually or with the support of a CAQDAS. After searching for material on the internet and the study of texts, has been identified as MAXQDA software that fulfilled the needs of the analysis to be performed [14]. As the various CAQDAS, this software allows you to analyze with greater speed and a considerable quantity of data allowing to produce specific outputs.

In addition, a data processing program also serves as data memory, which allows you to maintain stored data and save them periodically as a single data file on your computer or other external storage media. Also having an active program of memos, MAXQDA allows you to create a diary in which you write annotations on the encoding process. It is fundamental importance is then the characteristics of the severity of this type of software for qualitative research, as they allow "to develop conceptual and theoretical reflection on the data collected and the ability to constantly reorganize the material, encouraging mutual dialogue between theory and data typical of qualitative research".

\section{Training Proposal}

Globalization has brought profound changes from the framework of economic nationalism that prevailed in the Seventies of the last century. The impact have had significant changes in a field related to development, namely, that of training. In the Sixties, spread an optimistic idea compared to the world of education and extra-curricular training because it was believed that education would allow an improvement of living conditions and a more equitable distribution of social opportunities. The improvement in their level of education and professional qualification lead to claim that it was behind the development and economic well-being.

The school was then seen as a means of social emancipation. With the economic crisis of the Seventies, there has been a change in the consideration of the school, which is evaluated as a parking area of welfare policies. In the Eighties, the Theory of Human Capital says that evaluated the investment in education as a necessary factor of balance and economic development. This theory argues that education is a form of investment and the demand for education is comparable to any other question of economic good. The expansion of education is seen as a channel through which there can be a greater equality in income distribution.

"Today more than ever, education is dominated by the discourse of economic rationalism setting [...] centered on the cult of efficiency " and the removal of the intervention of the various governments in favor of a new management of the education" [15]. The economic rationality, with which it is assumed that the individual is acting on the labor market for the protection of their own selfish interests and to maximize the utility of the choices, is elevated to rational tout court. In this context, the discourse on education is redefined in terms of the language of the Theory of Human Capital.

"However, there is concomitantly the coming of new demands most of all from the new generations, in relation to the welfare crisis that we are experiencing. The young become the mouthpiece for new instances for "a question of individual responsibility that demands to be certified, provided it is left free to develop and organize however, one man project that aims to re-read, with the state and business the fundamentals of a new social contract". This means a paradigm shift not only economic but also social. The welfare state is no longer seen as a 
series of supporting policy, but becomes active as it implies a responsibility of trainees.

European policies promoted in recent years (the Lisbon Strategy; Europe 2020), are the keystone of the training policies of long life learning, that is, a formation that points to qualify always people throughout their lives. But if on the one hand, there is the "request" of the active participation of citizens in this new social pact. It is also true that, on the other hand, that in this time of crisis, it is necessary that the various social actors promote a number of conditions to enable people to choose their own life project.

It is at this crossroads that training and Capability Approach meet, because if you have to fulfill the objectives set by the European strategies, particularly that of Lisbon, "it is, however, recovering A. Sen (2000) , to go beyond the concept of human capital , after recognizing the importance and scope", assuming the perspective of a welfare of capabilities, rather than a simple welfare of skills". This new way of thinking about the welfare poses a challenge to the Educational Sciences and Pedagogy.

Returning to reality investigated by this research, the school is not the only social actor that should absorb as the burden of these changes, but much more a network of social actors, both public and private, make concrete opportunities for learning in those formal and informal context, allowing the maximum degree of freedom to act their capabilities in the realization of their project to life.

\subsection{Kolb Cycle}

A barging table becomes a training program for the social actors themselves who decide to get together and to formulate a project. This type of strategy is a direct reference to the tradition of Experiential Learning and especially the phases of the Kolb Cycle [16] [17]. In fact, in the first phase of the multi-stakeholder table, the various actors are confronted about their experiences and different points of view with which to address the issue of reception and integration of unaccompanied minors, and more generally the formation of adolescents.

At the first stage of confrontation, followed by another in which the different positions are used to formulate a theoretical model shared between the parties. This theoretical model could be studied and formulated in the first instance by a multidisciplinary team at a university and then discussed with the other social actors, so that they can make the changes needed to arrive at a single shared model to be tested in a later stage. Finally, as expected from the Kolb Cycle, after the experimentation of the project and training, there is a review of the results obtained during the trial.

The American scholar in formulating his thoughts in this Experiential Learning refers to a part in the thinking of John Dewey, which emphasizes "how significant is the meeting point between personal development, work and education. This synthesis has, moreover, the form of the process, as well as in Dewey is important to note the underscore consistency dynamics of this process ". It refers to the process of learning cycle of Lewin and has a circular shape, in the sense that the "Concrete experience is seen as the beginning and end of each learning process.

In the case of this research, various social actors find themselves not only around a table with bureaucratic purposes, but first perform a learning process for which on the one hand, stabilize the network on the territory, on the other formulate a plan for the multi-stakeholder education and training of children who are the target group of this process.

\subsection{School on Active Citizenship}

The proposal, which you want to present as a model for testing a path of education and training for children, has been formulated with the aim of bringing out those that are the capabilities of minors and potential for dissemination and sustainability of democracy multicultural projects not only in our country but also building bridges with the countries of origin of unaccompanied minors.

The school of active citizenship coast consists of the main part of a reciprocal collaboration between literacy, workshops and training courses on democracy. The triangulation of learning is accomplished through the training process to the democracies. All that is learned in the field of literacy and tested in the laboratories of context, can be implemented with an added value and so to make it useful in order to formulate plans for the sustainability of multi- and inter- cultural democracies between the countries of origin and host countries.

All activities that take place within the core of the school of active citizenship, have then practical implications. In fact, children who learn a whole range of knowledge, skills and new skills, have to invest them in real assets. So some workshops and vocational training surround the core, in order to create a portfolio of skills for each minor to be spent later in mixed management.

But the school of active citizenship does not have the only purpose of creating businesses that can support from a financial point of view, but also the project itself. A part of the core of the school was in fact the training to democracy, so these businesses should not be separated from the second purpose of this project, namely, the sustainability of intercultural democracies, with the promotion of projects between host countries and countries of origin, in order to favor the creation of conditions for the development of democracies in developing 
countries. In practice minors could be gradually incorporated into the labor market through vocational training. This would allow them to become progressively autonomous. In the meantime, developing a sense of responsible participation in society and in intercultural democracies.

\section{Conclusion}

This study of the reality of MSNA and the various training to citizenship, showed primarily a geography of the phenomenon extended to almost all the national territory, with peaks of concentration in some areas distributed from North to South. The reality has been investigated with a mixed methodology, which allowed on one hand to define a statistical point of view with the study of international, national and local report.

On the other hand, the tools of ethnographic method made it possible to get the differences between the contexts that constituted the fieldwork (Venice, Trento, Florence, Bari and Catania). The problem and research hypotheses were not defined a priori but after a reasonable time of the fieldwork, which has allowed us to understand better the issues that affect the reception and especially the integration of these children.

During the second year of research, a main issue emerged and it was that one of the transition to the coming on age of unaccompanied minors. These minors are called in the jargon of the community, "the limbic" because they live waiting for their documents or to find a job in order to continue to live in our country with a regular permit. But this social integration is very difficult because of bureaucraticadministrative plan is predominant with respect to the path of education and training. The families make pressure and it is dictated by the fact that to undertake the journeys of hope, the families often contract debts that the children has to rescue coming to work in rich Europe.

In the analysis of interviews with educators and the materials collected by the LabCity emerges that there is a need to promote integration policies. But most of all it is important to create learning environments that enable these children to enhance their skills, from formal to informal, as well as to make them active citizens and then to be able to strengthen that are their capabilities in such a way to make them autonomous and responsible to their existence and to the society in which they live .

\section{Acknowledgements}

First and foremost, I would like to thank to my supervisor of this Ph.D Research, Prof. Umberto Margiotta, for the valuable guidance and advice. Besides, I would like to thank the other professors of SIREF (Società Italiana di Ricerca Educativa e
Formativa) which provide me valuable information as the guidance of my research.

\section{References}

[1] United Nations Department of Economic and Social Affairs/Population Division, 'World Population Prospects: The 2010 Revision, Volume I. Comprehnsive Tables'; http://esa.un.org/wpp/Documentation/pdf/WPP2010_Volu me-I_Comprehensive-Tables.pdf (2 luglio 2013).

[2] IOM (2011) 'World Migration Report 2010, The future of migration: building capacities for change';

http://publications.iom.int/bookstore/free/WMR2010_sum mary.pdf (3 luglio 2013).

[3] UNDP (2013), 'Human Development Report 2013, The Rise of the South: Human Progress in a Diverse World' http://hdr.undp.org/en/media/HDR_2013_EN_complete.pd f (04 luglio 2013).

[4] Unicef (2011) 'La condizione dell'infanzia nel mondo. Adolescenza. Il tempo delle opportunità' www.unicef.it/Allegati/Condizione_infanzia_nel_mondo _2011.pdf (20 agosto 2013).

[5] UNICEF (2012) 'La condizione dell'infanzia nel mondo 2012. Figli delle città' http://www.unicef.it/Allegati/SOWC_2012_ITA.pdf (15 luglio 2013)

[6] EMN (2010) 'Secondo Rapporto EMN Italia' http:// www.stranieriinitalia.it/briguglio/immigrazione-e.../rappemn-msna.pdf (5 settembre 2013).

[7] ISMU (2011) 'XVII Rapporto sulle migrazioni 2011'http://www.cnel.it/.../Comunicato_XVII_Rapp_Ismu _2011_definitivo1.pdf (02 dicembre 2013).

[8] Save the Children (2013) 'I piccoli schiavi invisibili. Dossier tratta 2013'

http://www.minori.it/sites/default/files/dossier_tratta_2013 .pdf (14 febbraio 2013).

[9] Cohen, L., Manion, L. and Morrison, K. (2011) Research Methods in Education, Routledge, Oxon.

[10] De Lillo (2010), Il mondo della ricerca qualitativa, UTET, Torino.

[11] Geertz, C. (1998) Interpretazione di culture, Il Mulino, Bologna.

[12] Hannerz, U. (2001) La diversità culturale, Il Mulino, Bologna.

[13] Bove, C. (2009) Ricerca educativa e formazione. Contaminazioni metodologiche, Franco Angeli, Milano.

[14] De Gregorio, E. and Lattanzi, P. F. (2011) Programmi per la ricerca qualtitativa, Franco Angeli, Milano.

[15] Margiotta, U. (2012), "Capitale formativo e welfare delle persone. Verso un nuovo contratto sociale", Metis, http://www.metis.progedit.com/anno-ii-numero-1/37saggi/191-capitale-formativo-e-welfare-delle-personeverso-un-nuovo-contratto-sociale.pdf (13 gennaio2013). 
International Journal of Technology and Inclusive Education (IJTIE), Volume 3, Issue 1, June 2014

[16] Minello, R. and Margiotta, U. (2011) Poiein. La pedagogia e le scienze della formazione, Pensa, Lecce.

[17] Di Nubila, R.D and Fedeli, M. (2010) L'esperienza: quando diventa fattore di formazione e di sviluppo. Dall'opera di David A. Kolb alle attuali metodologie e Experiential Learning, Pensa, Lecce. 